\title{
Bosutinib plus capecitabine for selected advanced solid tumours: results of a phase 1 dose-escalation study
}

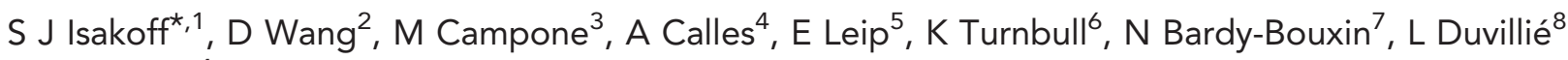 \\ and E Calvo ${ }^{4}$
}

${ }^{1}$ Division of Hematology and Oncology, Massachusetts General Hospital Cancer Center, and Harvard Medical School, 55 Fruit Street, Boston, MA 02114, USA; ${ }^{2}$ Phase I Clinical Trials Program, Henry Ford Hospital, 2799 West Grand Boulevard, Detroit, MI 48202, USA; ${ }^{3}$ Institut de Cancerologie de I'Quest-Rene Gauducheau, Saint Herblain, Nantes Cedex 44805, France; ${ }^{4}$ START Madrid, Centro Integral Oncológico Clara Campal, Hospital Madrid Norte-Sanchinarro, C/Oña n¹0, 28050 Madrid, Spain; ${ }^{5}$ Oncology Clinical Statistics, Pfizer Inc, 10 Fawcett Street, Suite 2013, Cambridge, MA 02138, USA; ${ }^{6}$ Oncology Clinical Development, Pfizer Inc, 10 Fawcett Street, Suite 2013, Cambridge, MA 02138, USA; ${ }^{7}$ Oncology Late Phase Strategy Development, Pfizer Global Research and Development, 23-25 av du Dr Lannelongue, Paris 75668, France and ${ }^{8}$ Oncology Clinical Development, Pfizer Global Research and Development, 23-25 av du Dr Lannelongue, Paris 75668, France

Background: This phase 1 study evaluated the maximum tolerated dose (MTD), safety, and efficacy of bosutinib (competitive Src/ Abl tyrosine kinase inhibitor) plus capecitabine.

Methods: Patients with locally advanced/metastatic breast, pancreatic, or colorectal cancers; cholangiocarcinoma; or glioblastoma received bosutinib plus capecitabine at eight of nine possible dose combinations using an 'up-down' design to determine the toxicity contour of the combination.

Results: Among 32 enrolled patients, none of the 9 patients receiving MTD (bosutinib $300 \mathrm{mg}$ once daily plus capecitabine $1000 \mathrm{mg} \mathrm{m}^{-2}$ twice daily) experienced dose-limiting toxicities (DLTs). Overall, 2 out of 31 (6\%) evaluable patients experienced DLTs (grade 3 neurologic pain $(n=1)$; grade 3 pruritus/rash and increased alanine aminotransferase $(n=1)$ ). Most common treatment-related adverse events (AEs) were diarrhoea, nausea, vomiting, palmar-plantar erythrodysesthesia (PPE), fatigue; most frequent grade 3/4 AEs: PPE, fatigue, and increased alanine/aspartate aminotransferase. Although diarrhoea was common, $91 \%$ of affected patients experienced maximum grade $1 / 2$ events that resolved. Best overall confirmed partial response or stable disease $>24$ weeks (all tumour types) was observed in 6 and $13 \%$ of patients.

Conclusions: In this population of patients with advanced solid tumours, bosutinib plus capecitabine demonstrated a safety profile similar to that previously reported for bosutinib or capecitabine monotherapy; limited efficacy was observed.

Advanced solid tumours are commonly treated with chemotherapeutic agents, including capecitabine, an oral 5-fluorouracil (5-FU) prodrug that induces cell death by inhibiting thymidylate synthase (TS; Koukourakis et al, 2008; XELODA Full Prescribing Information, 2013). Capecitabine monotherapy has shown efficacy in metastatic colorectal cancer (overall response rate (ORR): 19\%;
Van Cutsem et al, 2001) and in metastatic breast cancer (ORR: 15-28\%; Blum et al, 1999, 2001; Reichardt et al, 2003; Fumoleau et al, 2004; Amari et al, 2010; Blum et al, 2012). However, resistance to $5-\mathrm{FU}$, which is mediated primarily by TS upregulation, has been observed in several solid tumour models (Beck et al, 1994; Johnston et al, 1995; Peters et al, 2002).

*Correspondence: Dr SJ Isakoff; E-mail: sisakoff@partners.org

Received 23 December 2013; revised 1 July 2014; accepted 25 August 2014;

published online 7 October 2014

(c) 2014 Cancer Research UK. All rights reserved 0007-0920/14

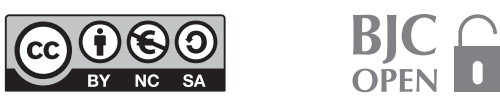


Preclinical findings show that inhibition of the proto-oncogene, nonreceptor tyrosine kinase Src (Summy and Gallick, 2003; Parsons and Parsons, 2004), synergises with 5-FU to restore chemosensitivity in pancreatic cancer cells (Ischenko et al, 2008) and to increase cytotoxicity in breast cancer models (Somlo et al, 2013). In addition, a study in non-small-cell lung cancer cells showed synergistic cytotoxic effects with the combination of the Src inhibitor dasatinib and the TS-inhibitor pemetrexed and demonstrated that pemetrexed-induced TS upregulation is blocked via Src inhibition; notably, in that study, pretreatment TS levels were positively correlated with Src levels, and increased Src and TS levels were significantly correlated with poorer survival in the donor patients (Ceppi et al, 2012). These findings suggest a potential role for the combination of a TS inhibitor and a Src inhibitor in countering 5-FU resistance.

Src has been recognised as a potential therapeutic target in a number of solid tumour settings, as Src dysregulation promotes tumour progression, metastasis, invasion, and angiogenesis (Talamonti et al, 1993; Verbeek et al, 1996; Summy and Gallick, 2003; Trevino et al, 2006; Park et al, 2007; Finn, 2008; Guarino, 2010; Gleixner et al, 2011). Src inhibition has been shown to exert antitumour activity in cellular and xenograft models of breast cancer (Finn et al, 2007; Huang et al, 2007; Jallal et al, 2007) and to exert antitumour and anti-invasive activity in colon (Golas et al, 2005; Serrels et al, 2006), head and neck (Johnson et al, 2005; Song et al, 2013), prostate (Nam et al, 2005), non-small-cell lung (Johnson et al, 2005), glioblastoma (Du et al, 2009), and sarcoma (Shor et al, 2007) cancers in preclinical studies.

Dasatinib and bosutinib are dual inhibitors of the Src and Abl tyrosine kinases (Mayer and Krop, 2010). An initial phase 1 study has evaluated the combination of dasatinib (100-140 mg daily) with capecitabine (800-1000 $\mathrm{mg} \mathrm{m}^{-2}$ twice daily) in advanced breast cancer $(n=52)$, resulting in an ORR of $22 \%$ and manageable tolerability (Somlo et al, 2013). Although the ORR was similar to that reported with capecitabine monotherapy in other studies (Blum et al, 1999, 2001; Reichardt et al, 2003; Fumoleau et al, 2004; Amari et al, 2010), the phase 1 study was not powered sufficiently to assess the efficacy contributions of dasatinib to the combination (Somlo et al, 2013), suggesting that further evaluation of Src inhibitors in combination with capecitabine is needed.

Bosutinib (SKI-606), which is approved in the United States (Bosulif Full Prescribing Information, 2013) and Europe (Bosulif Summary of Product Characteristics, 2013) for use in Philadelphia chromosome-positive chronic myeloid leukaemia, has been shown to inhibit Src and the growth of pancreatic tumour xenografts (Messersmith et al, 2009), the migration and invasion of breast cancer cells (Vultur et al, 2008), and the growth and invasion of prostate cancer cells and xenografts (Rabbani et al, 2010) in preclinical models. In addition, bosutinib at a dose of $400 \mathrm{mg}$ per day has shown limited activity (ORR: $5.5 \%$; median progressionfree survival (PFS): 9.9 weeks) and a manageable tolerability profile in a phase 2 study of patients $(n=73)$ with unselected, heavily pretreated advanced breast cancer (67\% hormone receptorpositive; Campone et al, 2012). Together, these preclinical and preliminary clinical findings support the feasibility of evaluating the combination of bosutinib and capecitabine in patients with select locally advanced or metastatic solid tumours. In the present study, the maximum tolerated dose (MTD) and the safety, tolerability, and antitumour activity of this combination are assessed in patients with advanced solid tumours.

\section{MATERIALS AND METHODS}

Study design. This study was originally planned as a phase $1 / 2$, multicentre, open-label study (ClinicalTrials.gov; Unique ID:
NCT00959946); the phase 1 portion was completed and the results are reported here. The phase 1 study used an 'up-down' doseescalation design (Ivanova and Wang, 2004) to determine the MTD of bosutinib plus capecitabine combination therapy in patients with selected solid tumours. The results of a simulation study showed that, compared with a specific $3+3$ design, this 'up-down' dose-escalation design allows more patients to be evaluated closer to the MTD and fewer at toxic dose levels (see Supplementary Materials). Bosutinib was administered orally once daily continuously, and capecitabine was administered orally twice daily on days 1 to 14 of each 21-day treatment cycle. Up to nine dose combinations, including three dose levels of bosutinib (200, 300 , and $400 \mathrm{mg}$ ) and three dose levels of capecitabine $(625,750$, and $1000 \mathrm{mg} \mathrm{m}^{-2}$ ), were selected as possible dose levels. The initial dose cohorts with two patients each were (i) bosutinib $200 \mathrm{mg}$ per day plus capecitabine $750 \mathrm{mg} \mathrm{m}^{-2}$ twice daily and (ii) bosutinib $300 \mathrm{mg}$ per day plus capecitabine $625 \mathrm{mg} \mathrm{m}^{-2}$ twice daily.

Additional cohorts could be enrolled at higher or lower dose levels based on the number of dose-limiting toxicities (DLTs; described below) observed during the first 21 days in the current cohort of two patients, the cumulative toxicity rate at that dose combination, and the current doses of bosutinib and capecitabine. Cohort enrollment was based on the rules presented in Table 1 (see Supplementary Materials for additional information). The 'up-down' dose-escalation design allowed up to nine dose combinations across the two drugs studied (Table 2). This design would also allow the possibility of achieving two concurrent MTD levels, one that would maximise bosutinib and the other that would maximise capecitabine, in the event that increasing both concurrently proved untenable. Patients were enrolled at the next dose level when two evaluable patients at the same dose level had been evaluated for the first 21-day treatment cycle and had received at least 14 doses of bosutinib and at least 10 doses of capecitabine or experienced a DLT, whichever occurred first, until a total of 24 evaluable patients were assessed. If a patient withdrew from the study before completing the 21-day period without experiencing a DLT, another patient was enrolled to replace that patient at the current dose combination.

DLTs were defined as any of the following treatment-related events that occurred during the first 21-day cycle: grade 3/4 nonhaematologic adverse event (AE), including nausea, vomiting, or diarrhoea despite optimal medical therapy, and asthenia lasting more than 3 days; grade 4 haematologic AE; or delayed recovery from one of the above AEs, causing delay of treatment by at least 3 weeks.

\begin{tabular}{|c|c|c|}
\hline $\begin{array}{l}\text { Number of } \\
\text { DLTs in current } \\
\text { cohort }^{a}\end{array}$ & $\begin{array}{l}\text { Cumulative } \\
\text { toxicity rate }\end{array}$ & Next enrollees \\
\hline 0 & $<33 \%$ & $\begin{array}{l}2 \text { Patients at } 1 \text { level higher for } \\
\text { bosutinib (capecitabine unchanged) } \\
2 \text { patients at } 1 \text { level higher for } \\
\text { capecitabine (bosutinib unchanged) }\end{array}$ \\
\hline 0 & $\geqslant 33 \%$ & $\begin{array}{l}2 \text { Patients at } 1 \text { level lower for } \\
\text { bosutinib and } 1 \text { level higher for } \\
\text { capecitabine }\end{array}$ \\
\hline 1 or 2 & $<33 \%$ & $\begin{array}{l}2 \text { Patients at } 1 \text { level higher for } \\
\text { bosutinib and } 1 \text { level lower for } \\
\text { capecitabine }\end{array}$ \\
\hline 1 or 2 & $\geqslant 33 \%$ & $\begin{array}{l}\text { If the current bosutinib level }> \\
\text { capecitabine, } 2 \text { subjects at } 1 \text { level } \\
\text { lower bosutinib (capecitabine } \\
\text { unchanged). Otherwise, } 2 \text { subjects } \\
\text { at } 1 \text { level lower capecitabine } \\
\text { (bosutinib unchanged) }\end{array}$ \\
\hline $\begin{array}{l}\text { Abbreviation: DLT= } \\
{ }^{\mathrm{a}} \text { Out of two patients }\end{array}$ & niting toxicity. & \\
\hline
\end{tabular}


The MTD for bosutinib plus capecitabine was defined as the highest dose level at which less than $33 \%$ of patients experienced a DLT.

Written informed consent was obtained from all patients before enrollment. The protocol was reviewed and approved by the Ethics Committees/Institutional Review Boards of the participating institutions, and the study was conducted according to the Declaration of Helsinki and European Good Clinical Practice requirements.

Eligibility criteria. Eligible patients were men and women aged $\geqslant 18$ years with a confirmed pathologic diagnosis of locally advanced or metastatic breast cancer, pancreatic cancer, colorectal cancer, cholangiocarcinoma, or glioblastoma that was not curable with approved regimens. Patients were also required to have at least one radiologically measurable lesion as defined by the Response Evaluation Criteria In Solid Tumors (RECIST), version 1.0, and an Eastern Cooperative Oncology Group Performance Status score of 0 to 2. Bone or skin could not be the only site of disease, and patients with clinically unstable primary or metastatic central nervous system tumours were ineligible. No prior treatment with Src inhibitors was permitted; however, prior treatment with capecitabine or 5-FU was allowed unless stopped for toxicity. No chemotherapy, investigational therapy, major surgery, or radiation therapy within 14 days of study treatment initiation was allowed. Patients with any other major illness, including a history of clinically significant or uncontrolled cardiac disease, serious active infection, uncontrolled major seizure disorder, or significant pulmonary disorder, were ineligible.

Safety and efficacy assessments. The primary safety objective was to determine the MTD of bosutinib plus capecitabine in patients with solid tumours by examining the DLT rates within the dose cohorts. All patients who received at least one dose of study treatment were included in the safety evaluation, which included the incidence of AEs, physical examination, laboratory evaluations, 12-lead electrocardiogram, and left ventricular ejection fraction measurement. Safety events were graded for severity according to the National Cancer Institute Common Terminology Criteria for Adverse Events, version 3.0.

Tumour assessments were performed for all patients at screening, and response was assessed every 6 weeks until disease progression or treatment discontinuation. No primary efficacy end point was specified; the secondary objective of antitumour activity was assessed based on best confirmed overall response according to

Table 2. Dose combinations for determination of the MTD

\begin{tabular}{|c|c|c|c|}
\hline \multirow[b]{2}{*}{ Capecitabine, $\mathrm{mg} \mathrm{m}^{-2}$ twice daily } & \multicolumn{3}{|c|}{ Bosutinib, mg per day } \\
\hline & $200, n$ & $300, n$ & $400, n$ \\
\hline 1000 & 4 & $9^{a, b}$ & $2^{c}$ \\
\hline 750 & $4^{d}$ & 4 & $2^{c}$ \\
\hline 625 & 2 & $5^{d, e}$ & \\
\hline \multicolumn{4}{|c|}{ 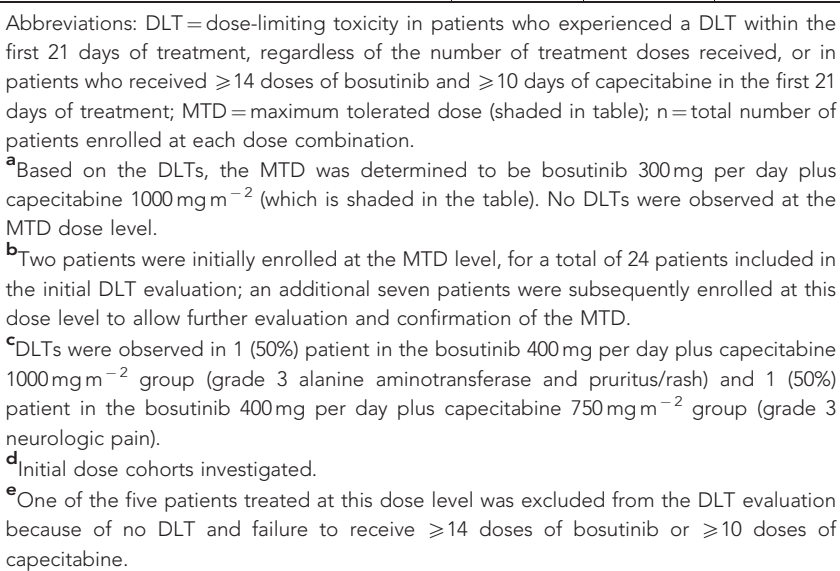 } \\
\hline
\end{tabular}

RECIST version 1.0 (Therasse et al, 2000) and ORR (confirmed complete response (CR) or partial response (PR)).

\section{RESULTS}

Patients. A total of 32 patients were enrolled in this phase 1 study between October 2009 and March 2011, among whom, the median age was 62 (range, 42-82) years (Table 3 ). The majority of patients had a diagnosis of colorectal cancer $(44 \%)$, breast cancer $(34 \%)$, or pancreatic cancer (16\%); cholangiocarcinoma and glioblastoma were each present in one patient. Most (69\%) patients had previously received at least five antitumour treatment regimens for locally advanced or metastatic disease; $22 \%$ of patients had previously received capecitabine treatment.

The median study duration was 81.0 days (range, 22-420 days), with a median duration of treatment of 63.5 days (range, 19-419 days). All patients discontinued the study, the primary reasons for which included disease progression $(n=26(81 \%))$, AEs $(n=4$ $(13 \%))$, death $(n=1(3 \%))$, and patient withdrawal $(n=1(3 \%))$.

Determination of the MTD. Because of the adaptive nature of the study design, all possible dose combinations shown in Table 2 were explored at least once, with the exception of bosutinib $400 \mathrm{mg}$ per day plus capecitabine $625 \mathrm{mg} \mathrm{m}^{-2}$ twice daily. The sequence of patient enrollment in each dose-escalation cohort is shown in Table 4. Based on the observed toxicity, the MTD was determined to be bosutinib $300 \mathrm{mg}$ per day plus capecitabine $1000 \mathrm{mg} \mathrm{m}^{-2}$ twice daily on days 1-14 of each 21-day treatment cycle, with no DLTs observed for the two patients treated at the MTD during the doseescalation phase. An additional seven patients were subsequently

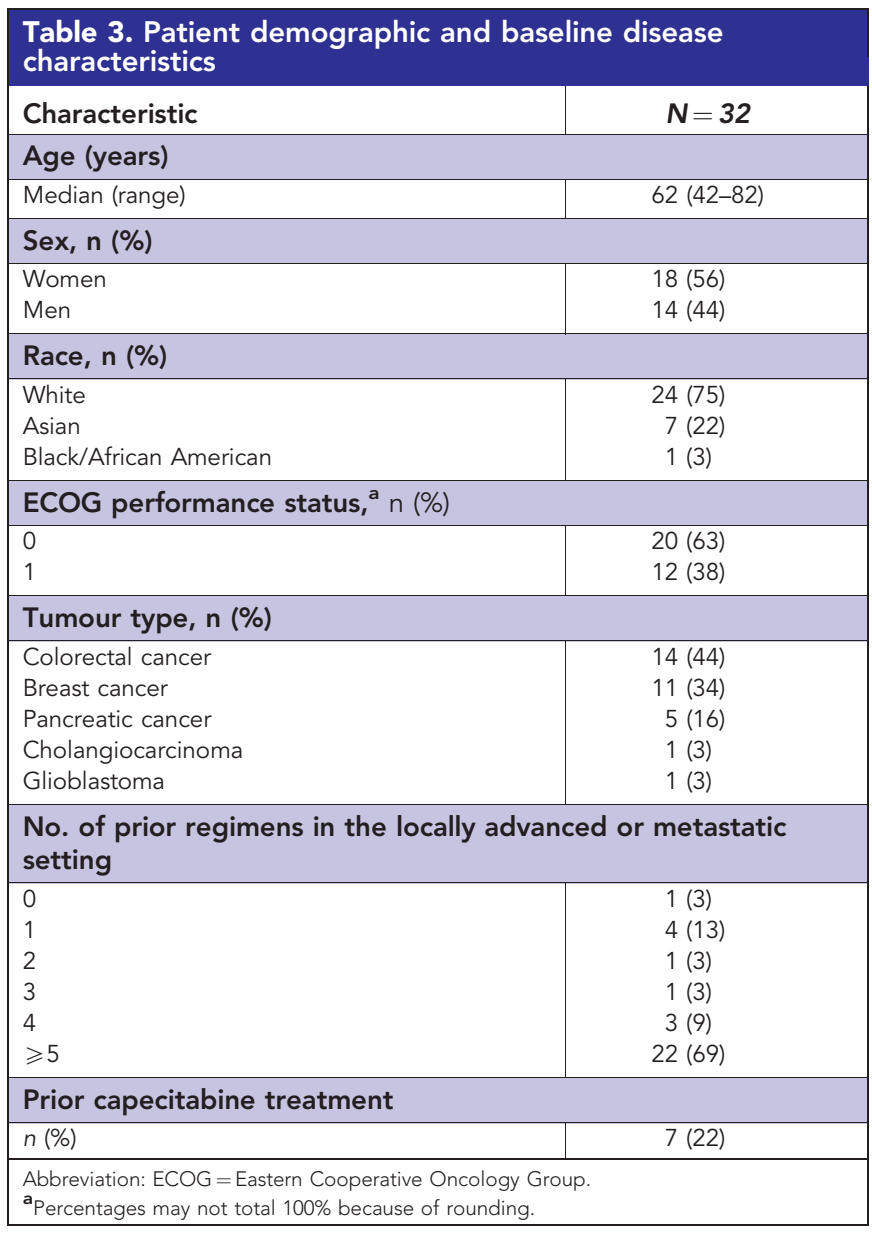




\begin{tabular}{|c|c|c|c|c|c|c|}
\hline \multicolumn{6}{|c|}{ Cohort } & \multirow[b]{2}{*}{$\begin{array}{c}\text { Next } \\
\text { dose cohort }\end{array}$} \\
\hline $\begin{array}{l}\text { Sequence } \\
\text { of cohort } \\
\text { enrollment }\end{array}$ & $\begin{array}{c}\text { Dose level } \\
\left(\mathrm{CAPE}\left(\mathrm{mg} \mathrm{m}^{-2}\right) /\right. \\
\text { BOS }(\mathrm{mg}))\end{array}$ & Number & $\begin{array}{c}\text { Patients } \\
\text { enrolled, n }\end{array}$ & $\begin{array}{c}\text { Patients } \\
\text { evaluable } \\
\text { for DLT, } n\end{array}$ & DLT & \\
\hline 1 & $750 / 200$ & C1 & 2 & 2 & None & $\mathrm{C} 3 / \mathrm{C} 4$ \\
\hline 2 & $625 / 300$ & $\mathrm{C} 2$ & $3^{b}$ & 2 & None $^{c}$ & $\mathrm{C7}$ \\
\hline 3 & $750 / 300$ & C3 & 2 & 2 & None & $\mathrm{C} 5 / \mathrm{C6}$ \\
\hline 4 & $1000 / 200$ & C4 & 2 & 2 & None & $C 8^{d}$ \\
\hline 5 & $750 / 400$ & $\mathrm{C5}$ & 2 & 2 & 1 DLT: Grade 3 neurologic pain & C9 \\
\hline 6 & $1000 / 300$ & C6 & 2 & 2 & None & C10 \\
\hline 7 & $625 / 200$ & $\mathrm{C7}$ & 2 & 2 & None & C11/C12 \\
\hline 8 & $750 / 300$ & C9 & 2 & 2 & None & $N A^{e}$ \\
\hline 9 & $1000 / 200$ & C8 & 2 & 2 & None $^{f}$ & NA \\
\hline 10 & $1000 / 400$ & C10 & 2 & 2 & $\begin{array}{l}1 \text { DLT in } 1 \text { patient: } \\
\text { Grade } 3 \text { ALT increased } \\
\text { Grade } 3 \text { itchy skin } \\
\text { Grade } 3 \text { skin rash }\end{array}$ & \\
\hline 11 & $750 / 200$ & C11 & 2 & 2 & None & $N A^{e}$ \\
\hline 12 & $625 / 300$ & $\mathrm{C} 12$ & 2 & 2 & None & $N A^{e}$ \\
\hline \multicolumn{7}{|c|}{ 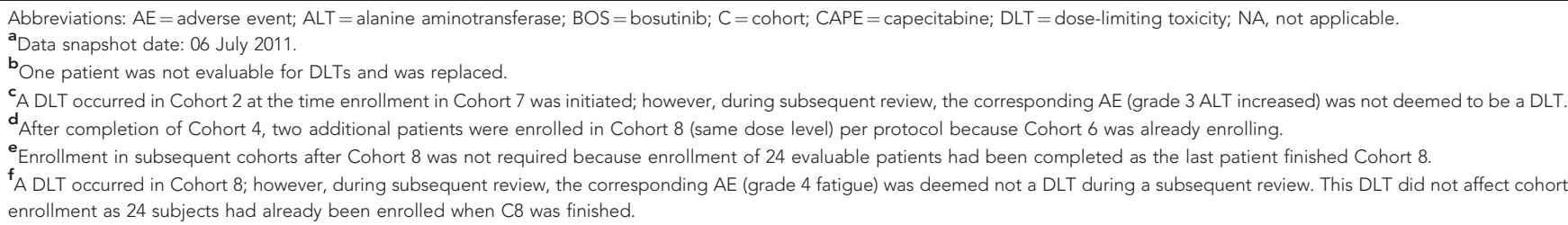 } \\
\hline
\end{tabular}

enrolled at the MTD to confirm the selected dose, and again no DLTs were observed. Only one MTD was identified for this combination.

Overall, 2 out of $31(6 \%)$ evaluable patients experienced DLTs. The first patient was a 56-year-old woman with metastatic breast cancer who was receiving bosutinib $400 \mathrm{mg}$ per day plus capecitabine $750 \mathrm{mg} \mathrm{m}^{-2}$ twice daily and experienced grade 3 neurologic pain on study day 5. Bosutinib $400 \mathrm{mg}$ per day was stopped on study day 8 and bosutinib $300 \mathrm{mg}$ per day was started on study day 14 , after the neurologic pain resolved to grade 1 . The second patient was a 58year-old woman with metastatic breast cancer who was receiving bosutinib $400 \mathrm{mg}$ per day plus capecitabine $1000 \mathrm{mg} \mathrm{m}^{-2}$ twice daily who experienced grade 3 increased alanine aminotransferase (ALT) and pruritus/rash, both of which resolved following temporary discontinuation of bosutinib. These DLTs were considered to be treatment related; association with either bosutinib or capecitabine treatment was not determined. One additional patient receiving bosutinib $200 \mathrm{mg}$ per day plus capecitabine $1000 \mathrm{mg} \mathrm{m}^{-2}$ twice daily experienced grade 2 fatigue, which later progressed to grade 4 severity one day after the 21-day DLT assessment period; because of this timing the event did not meet the DLT criteria. The recommended MTD of the combination would not have changed if this subject met the DLT criteria. Notably, DLTs resolved after temporarily stopping treatment and none of these events were considered by the investigators to be serious AEs.

Safety and tolerability. All $32(100 \%)$ patients experienced at least one treatment-emergent AE among whom 29 (91\%) experienced at least one treatment-related (bosutinib and/or capecitabine) AE. The most common treatment-related AEs, overall as well as within the MTD cohort, were diarrhoea, nausea, palmar-plantar erythrodysesthesia (PPE), fatigue, and vomiting (Table 5). A total of 15 (47\%) patients experienced at least one grade $3 / 4$ treatment-related AE, most frequently PPE, increased ALT, and increased aspartate aminotransferase (AST; Table 5). Ten (31\%) patients experienced at least one serious $\mathrm{AE}$, including anaemia, atrial fibrillation, constipation, gastrointestinal obstruction, asthenia, chest pain, hemiparesis, renal impairment, acute respiratory distress syndrome, dyspnoea $(n=1$ each); bronchitis $(n=2)$, and disease progression (glioblastoma multiforme $(n=1)$, malignant neoplasm $(n=2)$; pancreatic cancer $(n=1))$.

Although diarrhoea was common $(n=23(72 \%)), 91 \%$ (21 out of 23) of patients with diarrhoea experienced only maximum grade 1 or 2 events, all patients had their diarrhoea resolved (median (range) cumulative duration of 10 (1-267) days), and no patient discontinued treatment because of diarrhoea, suggesting that events were manageable. Two (9\%) patients required dose interruption, and one (4\%) patient had dose reduction in order to manage their diarrhoea events. Treatment-emergent AEs of grade 3/4 ALT or AST elevations were reported in three (9\%) and three $(9 \%)$ patients, respectively; these events were managed by dose interruption in two and two patients, respectively, and all resolved with no patient discontinuing treatment. Treatmentrelated haematologic AEs were relatively uncommon, with one patient each experiencing maximum grade 1 or 2 leukopenia, lymphopenia, neutropenia, and thrombocytopenia. Cardiac events were reported in five (16\%) patients; four of these subjects with events considered drug related, one of which was a serious $\mathrm{AE}$ of atrial fibrillation observed in a patient with a history of peripheral arterial occlusive disease and hypertension, who was receiving Warfarin. Prolonged QT (grade 2) was reported in two patients, and decreased ejection fraction (grade 3 ) was reported in one patient; all had a prior history of cardiac disease. Most of the resolved cardiac events were transient, with cumulative median (range) duration of $16(10-22)$ days, and all but one of the patients (grade 3 decreased ejection fraction) had their cardiac events resolve. Cumulative duration for this patient is unknown.

Grade 3/4 laboratory values were reported in nine $(28 \%)$ patients on treatment, and included abnormal sodium values 
Table 5. Treatment-related AEs and treatment modifications and discontinuations due to AEs

\begin{tabular}{|c|c|c|c|c|}
\hline \multirow[b]{2}{*}{ Treatment-related AEs } & \multicolumn{2}{|c|}{ MTD cohort $(n=9)$} & \multicolumn{2}{|c|}{ All patients $(N=32)$} \\
\hline & Any grade & Grade $3 / 4$ & Any grade & Grade 3/4 \\
\hline Any $\mathrm{AE}_{,}^{\mathrm{a}} \mathrm{n}(\%)$ & $9(100)$ & $4(44)$ & $29(91)$ & $15(47)$ \\
\hline Diarrhoea & 8 (89) & 0 & $21(66)$ & $2(6)$ \\
\hline Nausea & $4(44)$ & 0 & $13(41)$ & 0 \\
\hline PPE & $3(33)$ & $1(11)$ & $10(31)$ & $3(9)$ \\
\hline Fatigue & $4(44)$ & 0 & $9(28)$ & $2(6)$ \\
\hline Vomiting & $2(22)$ & 0 & $8(25)$ & 0 \\
\hline Decreased appetite & $2(22)$ & 0 & $5(16)$ & 0 \\
\hline Increased ALT & $2(22)$ & $1(11)$ & $4(13)$ & $3(9)$ \\
\hline Mucosal inflammation & $2(22)$ & 0 & $4(13)$ & 0 \\
\hline Increased AST & $2(22)$ & $2(22)$ & $3(9)$ & $3(9)$ \\
\hline Rash & $1(11)$ & 0 & $3(9)$ & $1(3)$ \\
\hline Constipation & $1(11)$ & 0 & $3(9)$ & 0 \\
\hline Gastroesophageal reflux disease & 0 & 0 & $3(9)$ & 0 \\
\hline Pain in extremity & 0 & 0 & $2(6)$ & 0 \\
\hline Peripheral sensory neuropathy & 0 & 0 & $3(9)$ & 0 \\
\hline Dyspnoea & 0 & 0 & $2(6)$ & $1(3)$ \\
\hline Abdominal pain & $1(11)$ & 0 & $4(13)$ & 0 \\
\hline Dry skin & 0 & 0 & $2(6)$ & 0 \\
\hline Headache & $1(11)$ & 0 & $2(6)$ & 0 \\
\hline Flatulence & $1(11)$ & 0 & $2(6)$ & 0 \\
\hline Electrocardiogram QT prolonged & 0 & 0 & $2(6)$ & 0 \\
\hline Decreased ejection fraction & $1(11)$ & $1(11)$ & $1(3)$ & $1(3)$ \\
\hline Hypophosphatemia & $1(11)$ & $1(11)$ & $1(3)$ & $1(3)$ \\
\hline Atrial fibrillation & 0 & 0 & $1(3)$ & $1(3)$ \\
\hline Chest pain & 0 & 0 & $1(3)$ & $1(3)$ \\
\hline Hypersensitivity & 0 & 0 & $1(3)$ & $1(3)$ \\
\hline Neuralgia & 0 & 0 & $1(3)$ & $1(3)$ \\
\hline Pruritus & 0 & 0 & $1(3)$ & $1(3)$ \\
\hline $\begin{array}{l}\text { Treatment modifications and } \\
\text { discontinuations due to AEs, } n(\%)\end{array}$ & \multicolumn{2}{|c|}{ MTD cohort $(n=9)$} & \multicolumn{2}{|c|}{ All patients $(N=32)$} \\
\hline \multicolumn{5}{|l|}{ Dose reduction } \\
\hline $\begin{array}{l}\text { Bosutinib } \\
\text { Capecitabine }\end{array}$ & \multicolumn{2}{|c|}{$1(11)$} & \multicolumn{2}{|c|}{$3(9)$} \\
\hline \multicolumn{5}{|l|}{ Dose interruption } \\
\hline $\begin{array}{l}\text { Bosutinib } \\
\text { Capecitabine }\end{array}$ & \multicolumn{2}{|c|}{$3(33)$} & \multicolumn{2}{|c|}{$16(50)$} \\
\hline \multicolumn{5}{|l|}{ Discontinuation } \\
\hline Discontinued treatment $^{b}$ & \multicolumn{2}{|c|}{$1(11)$} & \multicolumn{2}{|c|}{$4(13)$} \\
\hline \multicolumn{5}{|c|}{ 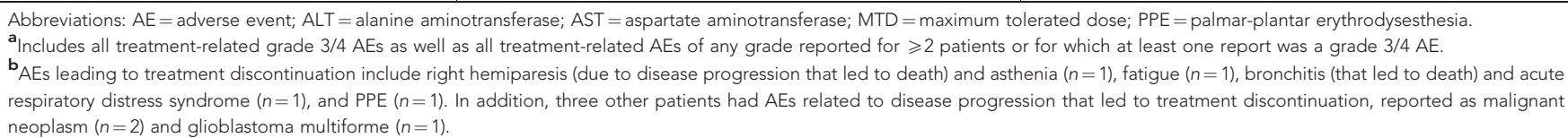 } \\
\hline
\end{tabular}

$(n=3)$; international normalised ratio, partial thromboplastin time, phosphorous, calcium, ALT, and prothrombin time $(n=2$ each); and glucose, AST, and haemoglobin ( $n=1$ each). Grade $3 / 4$ partial thromboplastin time and prothrombin time increases were reported in one patient both at baseline and on treatment. Based on electrocardiogram laboratory data, no patient had a QT or corrected QT (QTc) interval greater than $500 \mathrm{~ms}$.

Bosutinib and capecitabine dose modifications due to AEs are shown in Table 5. Bosutinib dose reduction and interruption due to an $\mathrm{AE}$ occurred in $9 \%$ and $34 \%$ of patients, respectively. Capecitabine dose reduction and interruption due to an AE occurred in $13 \%$ and $50 \%$ of patients, respectively. Four (13\%) patients experienced AEs that led to treatment discontinuation; AEs included right hemiparesis (due to disease progression that led to death) and asthenia $(n=1)$, fatigue $(n=1)$, bronchitis (that led to death) and acute respiratory distress syndrome $(n=1)$, and PPE syndrome $(n=1)$. In addition, three other patients had AEs related to disease progression that led to treatment discontinuation, reported as malignant neoplasm $(n=2)$ and glioblastoma multiforme $(n=1)$. Of the AEs that led to treatment discontinuation, only PPE and fatigue were considered treatment related.

Overall, six (19\%) deaths occurred during the study, with five deaths occurring within 28 days of the last study dose. Five of the six deaths were due to disease progression (primary diagnoses of pancreatic cancer $(n=2)$; breast cancer, glioblastoma multiforme, and colorectal cancer $(n=1$ each)), whereas the other was due to an unrelated AE of bronchial infection $(n=1)$. None of the deaths were considered drug related.

Antitumour activity. Among the intent-to-treat population $(n=32)$, one patient with breast cancer and one patient with colorectal cancer achieved a confirmed PR; no patient achieved a 
CR (ORR: 6\% (95\% CI: 1-21\%)). Stable disease (SD) lasting $\leq 24$ weeks was observed in 10 patients (breast cancer $(n=3)$; colorectal cancer $(n=7)$ ); SD lasting $>24$ weeks was observed in an additional 4 patients (breast cancer $(n=2)$; colorectal cancer $(n=2))$. None of the patients with pancreatic cancer, cholangiocarcinoma, or glioblastoma achieved a response or SD. A total of 15 patients (cholangiocarcinoma $(n=1)$; colorectal cancer $(n=4)$; breast cancer $(n=5)$; and pancreatic cancer $(n=5))$ had a best response of progressive disease. The response status of the patient with glioblastoma was indeterminate because the patient did not have any post-baseline tumour assessments and discontinued treatment before their week 6 assessment because of an AE.

\section{DISCUSSION}

The primary purpose of this study was to determine the MTD of bosutinib plus capecitabine in patients with select locally advanced or metastatic solid tumours. The MTD of this treatment combination was bosutinib $300 \mathrm{mg}$ per day plus capecitabine $1000 \mathrm{mg} \mathrm{m}^{-2}$ twice daily on days 1-14 of each 21 -day cycle.

A challenge in developing combination regimens incorporating a novel agent is whether the chemotherapy dose should be maximised with increasing doses of the novel agent, or whether the novel agent should be maximised with increasing doses of chemotherapy. The 'up-down' design allows for both possibilities to be explored, with the possibility of achieving up to three MTD levels for the combination. A similar 'up-down' design was used in a recent phase 1 study to evaluate the MTD of neratinib in combination with temsirolimus in patients with solid tumours (Gandhi et al, 2014).

The $3+3$ design is the most common method for dose evaluation in phase 1 studies and has the advantages of ease of implementation and interpretation, together with the requirement for smaller numbers of patients (Le Tourneau et al, 2009; Liu et al, 2013). However, drawbacks of this method include the need for a large number of dose escalation steps (e.g., $\geqslant 6$ dose levels) and treatment of many patients at subtherapeutic doses, as well as uncertainty surrounding the recommended phase 2 dose identified (Le Tourneau et al, 2009). In contrast, the 'up-down' design used in the present study allows for exploration of more dose combinations. Although the 'up-down' design allows for a more definitive identification of the MTD, the additional dose combinations evaluated require enrollment of additional patients. The simulation study also demonstrated that, compared with a specific $3+3$ design, more patients are evaluated closer to the MTD and fewer patients at toxic dose levels using the 'up-down' design. Moreover, the 'up-down' design mitigates the underestimation of the MTD that is associated with the $3+3$ design.

Notably, the MTD for bosutinib (300 mg per day) in combination with capecitabine in this study is lower than the therapeutic dose identified for bosutinib monotherapy in previous studies$500 \mathrm{mg}$ per day in patients with chronic/advanced phase CML (Cortes et al, 2011, 2012) and $400 \mathrm{mg}$ per day in patients with advanced solid tumours (Daud et al, 2012). In addition, the MTD identified for capecitabine ( $1000 \mathrm{mg} \mathrm{m}^{-2}$ twice daily) in this study is lower than the $1250 \mathrm{mg} \mathrm{m}^{-2}$ twice-daily dose recommended by the US Food and Drug Administration for metastatic breast cancer (XELODA Full Prescribing Information, 2013). However, retrospective analysis of medical and pharmacy records from 141 patients with metastatic breast cancer treated with capecitabine $1250 \mathrm{mg} \mathrm{m}^{-2}$ twice daily demonstrated greater toxicity at that dose than previously reported in clinical studies, supporting a starting dose of $1000 \mathrm{mg} \mathrm{m}^{-2}$ twice daily (Hennessy et al, 2005). Thus, the MTD dose of capecitabine identified in the current study (1000 $\mathrm{mg} \mathrm{m}^{-2}$ twice daily) may be better aligned with clinical practice than the $1250 \mathrm{mg} \mathrm{m}^{-2}$ twice-daily dose, and it is within the range of doses (1000-1250 $\mathrm{mg} \mathrm{m}^{-2}$ twice daily) recommended by the National Comprehensive Cancer Network (National Comprehensive Cancer Network, 2014).

In the present study, the combination of bosutinib and capecitabine (all dose combinations) was well tolerated, which might reflect the fact that $88 \%$ of patients received bosutinib at doses lower than $400 \mathrm{mg}$ per day and 53\% received capecitabine at a dose lower than $1000-1250 \mathrm{mg} \mathrm{m}^{-2}$ twice daily. Comparing AE incidence between the MTD cohort $(n=9)$ and all patients excluding those receiving the MTD $(n=23)$, incidence was increased in MTD-treated patients for AEs commonly reported with bosutinib (i.e., diarrhoea, $89 \%$ vs 57\%; increased ALT, $22 \%$ vs $9 \%$; increased AST, $22 \%$ vs $4 \%$ ), suggesting efficient selection of the MTD for bosutinib. In contrast, the most frequent AE reported with capecitabine across clinical trials-PPE (i.e., hand-foot syndrome)was not elevated in patients receiving the MTD versus all other patients (33\% vs 30\%); it is unclear whether assessment of a higher dose of capecitabine (e.g., $1250 \mathrm{mg} \mathrm{m}^{-2}$ twice daily) in the present study would have yielded different outcomes.

Consistent with the known $\mathrm{AE}$ profiles for bosutinib and capecitabine monotherapy, the $\mathrm{AE}$ profile of the combination of bosutinib and capecitabine was characterised mostly by mild gastrointestinal events (diarrhoea, nausea, vomiting), PPE, and fatigue. Grade 3/4 ALT and AST elevations were reported in $<10 \%$ of patients, and were manageable with no patient discontinuing treatment because of these AEs. The toxicity profile previously observed for bosutinib monotherapy in phase 1 and 2 studies in solid tumours was also generally characterised by mild gastrointestinal events that occurred early during treatment, and manageable ALT and AST elevations (Campone et al, 2012; Daud et al, 2012). Capecitabine has a well-established toxicity profile that is primarily characterised by high incidences of PPE, diarrhoea, nausea, vomiting, and stomatitis (Hennessy et al, 2005). Comparing the incidences of treatment-related AEs in the present study with those previously published for capecitabine monotherapy at a dose of $2510 \mathrm{mg} \mathrm{m}^{-2}$ daily in patients with paclitaxel-refractory metastatic breast cancer (Blum et al, 1999), certain treatment-related AEs occurred at lower incidence in the present study (all patients), including PPE (31\% vs 56\%), nausea (41\% vs 52\%), and vomiting (25\% vs $37 \%)$, whereas diarrhoea occurred at a higher rate in the present study (66\% vs 54\%). Notably, PPE events were not observed in studies evaluating bosutinib as monotherapy (Campone et al, 2012; Daud et al, 2012); thus, the occurrence of PPE events in the current study was likely attributable to capecitabine administration (XELODA Full Prescribing Information, 2013).

The tolerability results in this study are comparable with those seen in a phase 1 study designed to identify DLTs and the recommended phase 2 doses of dasatinib (another dual Abl/Src TKI) plus capecitabine in women with advanced breast cancer (Somlo et al, 2013). Consistent with the current study, some of the most common toxicities associated with dasatinib plus capecitabine observed in that study were gastrointestinal events (nausea, vomiting, and diarrhoea), PPE, headache, fatigue, and asthenia (Somlo et al, 2013). Moreover, the overall rate of treatment-related grade $3 / 4$ AEs reported here for bosutinib plus capecitabine (47\%) is also consistent with those reported for dasatinib plus capecitabine (50\%; Somlo et al, 2013).

The observed efficacy results should be considered limited, given the lack of a prespecified efficacy end point and the small number of patients evaluated at the MTD $(n=9)$. In this study, two patients (breast cancer, $n=1$; colorectal cancer, $n=1$ ) achieved a confirmed PR while receiving capecitabine at a lower dose than MTD (750 $\mathrm{mg} \mathrm{m}^{-2}$ twice daily) plus bosutinib $300 \mathrm{mg}$ per day. A phase 1 study of bosutinib monotherapy administered over a range of escalating doses in patients with advanced solid tumours demonstrated a confirmed PR in one patient with breast 
cancer, an unconfirmed CR in one patient with pancreatic cancer, and SD in five patients with colorectal or lung cancer lasting 22-50 weeks (Daud et al, 2012). In a phase 2 clinical study of single-agent bosutinib $400 \mathrm{mg}$ per day in heavily pretreated patients with advanced breast cancer unselected for hormone receptor status, four patients achieved a confirmed PR; each of these four patients had hormone receptor-positive breast cancer (Campone et al, 2012).

Studies of single-agent capecitabine $1250 \mathrm{mg} \mathrm{m}^{-2}$ twice daily for the treatment of patients with advanced or metastatic breast cancer have reported ORRs ranging from 15 to $28 \%$ and SD rates (any duration) ranging from 30 to $46 \%$ (Blum et al, 1999, 2001; Reichardt et al, 2003; Fumoleau et al, 2004; Amari et al, 2010). Patients with metastatic breast cancer treated with dasatinib plus capecitabine also achieved some clinical benefit in a phase 1 trial, as reflected by an ORR of $22 \%$ and an additional $30 \%$ experiencing SD lasting more than 24 weeks (Somlo et al, 2013). The overall SD rate of $50 \%$ observed for dasatinib plus capecitabine is consistent with the overall SD rate with bosutinib plus capecitabine observed here (44\%). In contrast, the ORR of $22 \%$ reported for the dasatinib plus capecitabine combination (Somlo et al, 2013) is higher than the ORR reported for capecitabine plus bosutinib reported here $(6 \%$; Somlo et al, 2013). The observation that none of the patients with pancreatic cancer in this study achieved a CR or PR with bosutinib plus capecitabine treatment might be expected based on the results of a previous phase 2 study showing that only 3 of 41 patients receiving single-agent capecitabine for pancreatic cancer achieved a PR (ORR, 7\%; Cartwright et al, 2002). However, comparisons of response rates across these studies are complicated by variations in study design and in patients' baseline characteristics. For example, the current study was a phase 1 study with a limited number of breast cancer patients, most of whom had received substantial amounts of prior therapy, and who had received capecitabine doses lower than those associated with single-agent efficacy $\left(1250 \mathrm{mg} \mathrm{m}^{-2}\right.$ twice daily; XELODA Full Prescribing Information, 2013).

The identification of patient subgroups most likely to benefit from therapy represents one of the major challenges in the development of novel targeted therapies in breast and other cancers; a number of clinical studies are currently ongoing to assess biomarkers predictive of response to dasatinib and other Src inhibitors in advanced solid tumours (Puls et al, 2011). For example, a phase 1 study of dasatinib in combination with capecitabine, oxaliplatin, and bevacizumab in patients with colorectal cancer showed that high expression levels of activated Src are predictive of improved response (Strickler et al, 2013). However, these studies are generally limited by the difficulties in assessing correlations between biomarker levels with response, given the small numbers of treatment responders (Strickler et al, 2013).

In conclusion, the combination of bosutinib plus capecitabine was associated with a manageable safety profile, which was primarily characterised by mild gastrointestinal events and similar to that previously observed for bosutinib or capecitabine monotherapy. Evidence supporting the efficacy of bosutinib plus capecitabine in patients with advanced solid tumours is limited; rigorous evaluation of the efficacy of bosutinib combined with capecitabine or with other agents for the treatment of advanced solid tumours, including breast cancer, awaits a suitably powered randomised clinical trial recruiting patients selected on the basis of Src inhibitor biomarkers that may optimise their treatment response.

\section{ACKNOWLEDGEMENTS}

We thank all of the participating patients and their families as well as the global network of investigators, research nurses, study coordinators, and operations staff. We also thank Drs Young Kim (formerly of Wyeth Research) and Charles Zacharchuk (Pfizer) for their contributions to the design and conduct of the study. Editorial/medical writing support was provided by Janetricks Chebukati, PhD of Scifluent, and Simon J. Slater, PhD, and Cynthia Gobbel, PhD, of Complete Healthcare Communications, Inc., and was funded by Pfizer. This study was sponsored by Pfizer Inc. SJI, DW, AC, and LD, nothing to disclose; MC, consultant and recipient of honoraria (Novartis and Servier); EL, KT, and NBB, employees of Pfizer and KT and NBB own stock in Pfizer; EC is the recipient of research funding (Pfizer, Novartis, Merck, Roche/ Genentech, PsiOxus, GSK, BMS, Boehringer Ingelheim, PharmaMar), consultant/advisor (Novartis, GSK, Pfizer, Roche/Genentech, Astellas), participant in speakers' bureau (Novartis, Astellas), recipient of honoraria (Novartis).

\section{REFERENCES}

Amari M, Ishida T, Takeda M, Ohuchi N (2010) Capecitabine monotherapy is efficient and safe in all line settings in patients with metastatic and advanced breast cancer. Jpn J Clin Oncol 40: 188-193.

Beck A, Etienne MC, Cheradame S, Fischel JL, Formento P, Renee N, Milano G (1994) A role for dihydropyrimidine dehydrogenase and thymidylate synthase in tumour sensitivity to fluorouracil. Eur J Cancer 30A: 1517-1522.

Blum JL, Barrios CH, Feldman N, Verma S, McKenna EF, Lee LF, Scotto N, Gralow J (2012) Pooled analysis of individual patient data from capecitabine monotherapy clinical trials in locally advanced or metastatic breast cancer. Breast Cancer Res Treat 136: 777-788.

Blum JL, Dieras V, Lo Russo PM, Horton J, Rutman O, Buzdar A, Osterwalder B (2001) Multicenter, phase II study of capecitabine in taxane-pretreated metastatic breast carcinoma patients. Cancer 92: 1759-1768.

Blum JL, Jones SE, Buzdar AU, LoRusso PM, Kuter I, Vogel C, Osterwalder B, Burger HU, Brown CS, Griffin T (1999) Multicenter phase II study of capecitabine in paclitaxel-refractory metastatic breast cancer. J Clin Oncol 17: $485-493$.

Bosulif Summary of Product Characteristics (2013) Pfizer Inc, Sandwich, Kent, UK.

Bosulif Full Prescribing Information (2013) Pfizer Inc, New York, NY, USA.

Campone M, Bondarenko I, Brincat S, Hotko Y, Munster PN, Chmielowska E, Fumoleau P, Ward R, Bardy-Bouxin N, Leip E, Turnbull K, Zacharchuk C, Epstein RJ (2012) Phase II study of single-agent bosutinib, a Src/Abl tyrosine kinase inhibitor, in patients with locally advanced or metastatic breast cancer pretreated with chemotherapy. Ann Oncol 23: 610-617.

Cartwright TH, Cohn A, Varkey JA, Chen YM, Szatrowski TP, Cox JV, Schulz JJ (2002) Phase II study of oral capecitabine in patients with advanced or metastatic pancreatic cancer. J Clin Oncol 20: 160-164.

Ceppi P, Rapa I, Lo Iacono M, Righi L, Giorcelli J, Pautasso M, Bille A, Ardissone F, Papotti M, Scagliotti GV (2012) Expression and pharmacological inhibition of thymidylate synthase and Src kinase in nonsmall cell lung cancer. Int J Cancer 130: 1777-1786.

Cortes JE, Kantarjian HM, Brummendorf TH, Kim DW, Turkina AG, Shen ZX, Pasquini R, Khoury HJ, Arkin S, Volkert A, Besson N, Abbas R, Wang J, Leip E, Gambacorti-Passerini C (2011) Safety and efficacy of bosutinib (SKI-606) in chronic phase Philadelphia chromosome-positive chronic myeloid leukemia patients with resistance or intolerance to imatinib. Blood 118: 4567-4576.

Cortes JE, Kim DW, Kantarjian HM, Brummendorf TH, Dyagil I, Griskevicius L, Malhotra H, Powell C, Gogat K, Countouriotis AM, Gambacorti-Passerini C (2012) Bosutinib versus imatinib in newly diagnosed chronic-phase chronic myeloid leukemia: results from the BELA trial. J Clin Oncol 30: 3486-3492.

Daud AI, Krishnamurthi SS, Saleh MN, Gitlitz BJ, Borad MJ, Gold PJ, Chiorean EG, Springett GM, Abbas R, Agarwal S, Bardy-Bouxin N, Hsyu PH, Leip E, Turnbull K, Zacharchuk C, Messersmith WA (2012) Phase I study of bosutinib, a src/abl tyrosine kinase inhibitor, administered to patients with advanced solid tumors. Clin Cancer Res 18: 1092-1100.

Du J, Bernasconi P, Clauser KR, Mani DR, Finn SP, Beroukhim R, Burns M, Julian B, Peng XP, Hieronymus H, Maglathlin RL, Lewis TA, Liau LM, Nghiemphu P, Mellinghoff IK, Louis DN, Loda M, Carr SA, Kung AL, Golub TR (2009) Bead-based profiling of tyrosine kinase phosphorylation 
identifies SRC as a potential target for glioblastoma therapy. Nat Biotechnol 27: 77-83.

Finn RS (2008) Targeting Src in breast cancer. Ann Oncol 19: 1379-1386.

Finn RS, Dering J, Ginther C, Wilson CA, Glaspy P, Tchekmedyian N, Slamon DJ (2007) Dasatinib, an orally active small molecule inhibitor of both the src and abl kinases, selectively inhibits growth of basal-type/ "triple-negative" breast cancer cell lines growing in vitro. Breast Cancer Res Treat 105: 319-326.

Fumoleau P, Largillier R, Clippe C, Dieras V, Orfeuvre H, Lesimple T, Culine S, Audhuy B, Serin D, Cure H, Vuillemin E, Morere JF, Montestruc F, Mouri Z, Namer M (2004) Multicentre, phase II study evaluating capecitabine monotherapy in patients with anthracycline- and taxanepretreated metastatic breast cancer. Eur J Cancer 40: 536-542.

Gandhi L, Bahleda R, Tolaney SM, Kwak EL, Cleary JM, Pandya SS, Hollebecque A, Abbas R, Ananthakrishnan R, Berkenblit A, Krygowski M, Liang Y, Turnbull KW, Shapiro GI, Soria JC (2014) Phase I study of neratinib in combination with temsirolimus in patients with human epidermal growth factor receptor 2-dependent and other solid tumors. J Clin Oncol 32: 68-75.

Gleixner KV, Mayerhofer M, Cerny-Reiterer S, Hormann G, Rix U, Bennett KL, Hadzijusufovic E, Meyer RA, Pickl WF, Gotlib J, Horny HP, Reiter A, Mitterbauer-Hohendanner G, Superti-Furga G, Valent P (2011) KIT-D816V-independent oncogenic signaling in neoplastic cells in systemic mastocytosis: role of Lyn and Btk activation and disruption by dasatinib and bosutinib. Blood 118: 1885-1898.

Golas JM, Lucas J, Etienne C, Golas J, Discafani C, Sridharan L, Boghaert E, Arndt K, Ye F, Boschelli DH, Li F, Titsch C, Huselton C, Chaudhary I, Boschelli F (2005) SKI-606, a Src/Abl inhibitor with in vivo activity in colon tumor xenograft models. Cancer Res 65: 5358-5364.

Guarino M (2010) Src signaling in cancer invasion. J Cell Physiol 223: 14-26.

Hennessy BT, Gauthier AM, Michaud LB, Hortobagyi G, Valero V (2005) Lower dose capecitabine has a more favorable therapeutic index in metastatic breast cancer: retrospective analysis of patients treated at M. D. Anderson Cancer Center and a review of capecitabine toxicity in the literature. Ann Oncol 16: 1289-1296.

Huang F, Reeves K, Han X, Fairchild C, Platero S, Wong TW, Lee F, Shaw P, Clark E (2007) Identification of candidate molecular markers predicting sensitivity in solid tumors to dasatinib: rationale for patient selection. Cancer Res 67: 2226-2238.

Ischenko I, Camaj P, Seeliger H, Kleespies A, Guba M, De Toni EN, Schwarz B, Graeb C, Eichhorn ME, Jauch KW, Bruns CJ (2008) Inhibition of Src tyrosine kinase reverts chemoresistance toward 5-fluorouracil in human pancreatic carcinoma cells: an involvement of epidermal growth factor receptor signaling. Oncogene 27: 7212-7222.

Ivanova A, Wang K (2004) A non-parametric approach to the design and analysis of two-dimensional dose-finding trials. Stat Med 23: 1861-1870.

Jallal H, Valentino ML, Chen G, Boschelli F, Ali S, Rabbani SA (2007) A Src/ Abl kinase inhibitor, SKI-606, blocks breast cancer invasion, growth, and metastasis in vitro and in vivo. Cancer Res 67: 1580-1588.

Johnson FM, Saigal B, Talpaz M, Donato NJ (2005) Dasatinib (BMS-354825) tyrosine kinase inhibitor suppresses invasion and induces cell cycle arrest and apoptosis of head and neck squamous cell carcinoma and non-small cell lung cancer cells. Clin Cancer Res 11: 6924-6932.

Johnston PG, Lenz HJ, Leichman CG, Danenberg KD, Allegra CJ, Danenberg PV, Leichman L (1995) Thymidylate synthase gene and protein expression correlate and are associated with response to 5-fluorouracil in human colorectal and gastric tumors. Cancer Res 55: 1407-1412.

Koukourakis GV, Kouloulias V, Koukourakis MJ, Zacharias GA, Zabatis H, Kouvaris J (2008) Efficacy of the oral fluorouracil pro-drug capecitabine in cancer treatment: a review. Molecules 13: 1897-1922.

Le Tourneau C, Lee JJ, Siu LL (2009) Dose escalation methods in phase I cancer clinical trials. J Natl Cancer Inst 101: 708-720.

Liu S, Cai C, Ning J (2013) Up-and-down designs for phase I clinical trials. Contemp Clin Trials 36: 218-227.

Mayer EL, Krop IE (2010) Advances in targeting SRC in the treatment of breast cancer and other solid malignancies. Clin Cancer Res 16: 3526-3532.

Messersmith WA, Rajeshkumar NV, Tan AC, Wang XF, Diesl V, Choe SE, Follettie M, Coughlin C, Boschelli F, Garcia-Garcia E, Lopez-Rios F, Jimeno A, Hidalgo M (2009) Efficacy and pharmacodynamic effects of bosutinib (SKI-606), a Src/Abl inhibitor, in freshly generated human pancreas cancer xenografts. Mol Cancer Ther 8: 1484-1493.
Nam S, Kim D, Cheng JQ, Zhang S, Lee JH, Buettner R, Mirosevich J, Lee FY, Jove R (2005) Action of the Src family kinase inhibitor, dasatinib (BMS-354825), on human prostate cancer cells. Cancer Res 65 9185-9189.

National Comprehensive Cancer Network (2014) NCCN Clinical Practice Guidelines in Oncology (NCCN Guidelines): Breast Cancer-Version 3. Available at http://hematologia-h12.com/onewebmedia/ NCCN\%20LMC\%202014.pdfAccessed on 24 February 2014.

Park SI, Shah AN, Zhang J, Gallick GE (2007) Regulation of angiogenesis and vascular permeability by Src family kinases: opportunities for therapeutic treatment of solid tumors. Expert Opin Ther Targets 11: $1207-1217$.

Parsons SJ, Parsons JT (2004) Src family kinases, key regulators of signal transduction. Oncogene 23: 7906-7909.

Peters GJ, Backus HH, Freemantle S, van Triest B, Codacci-Pisanelli G, van der Wilt CL, Smid K, Lunec J, Calvert AH, Marsh S, McLeod HL, Bloemena E, Meijer S, Jansen G, van Groeningen CJ, Pinedo HM (2002) Induction of thymidylate synthase as a 5 -fluorouracil resistance mechanism. Biochim Biophys Acta 1587: 194-205.

Puls LN, Eadens M, Messersmith W (2011) Current status of SRC inhibitors in solid tumor malignancies. Oncologist 16: 566-578.

Rabbani SA, Valentino ML, Arakelian A, Ali S, Boschelli F (2010) SKI-606 (Bosutinib) blocks prostate cancer invasion, growth, and metastasis in vitro and in vivo through regulation of genes involved in cancer growth and skeletal metastasis. Mol Cancer Ther 9: 1147-1157.

Reichardt P, Von Minckwitz G, Thuss-Patience PC, Jonat W, Kolbl H, Janicke F, Kieback DG, Kuhn W, Schindler AE, Mohrmann S, Kaufmann M, Luck H] (2003) Multicenter phase II study of oral capecitabine (Xeloda) in patients with metastatic breast cancer relapsing after treatment with a taxanecontaining therapy. Ann Oncol 14: 1227-1233.

Serrels A, Macpherson IR, Evans TR, Lee FY, Clark EA, Sansom OJ, Ashton GH, Frame MC, Brunton VG (2006) Identification of potential biomarkers for measuring inhibition of Src kinase activity in colon cancer cells following treatment with dasatinib. Mol Cancer Ther 5: 3014-3022.

Shor AC, Keschman EA, Lee FY, Muro-Cacho C, Letson GD, Trent JC, Pledger WJ, Jove R (2007) Dasatinib inhibits migration and invasion in diverse human sarcoma cell lines and induces apoptosis in bone sarcoma cells dependent on SRC kinase for survival. Cancer Res 67: 2800-2808.

Somlo G, Atzori F, Strauss LC, Geese WJ, Specht JM, Gradishar WJ, Rybicki A, Sy O, Vahdat LT, Cortes J (2013) Dasatinib plus capecitabine for advanced breast cancer: safety and efficacy in phase I study CA180004. Clin Cancer Res 19: 1884-1893.

Song Y, Sun X, Bai WL, Ji WY (2013) Antitumor effects of dasatinib on laryngeal squamous cell carcinoma in vivo and in vitro. Eur Arch Otorhinolaryngol 270: 1397-1404.

Strickler JH, McCall S, Nixon AB, Brady JC, Pang H, Rushing C, Cohn A, Starodub A, Arrowood C, Haley S, Meadows KL, Morse MA, Uronis HE, Blobe GC, Hsu SD, Zafar SY, Hurwitz HI (2013) Phase I study of dasatinib in combination with capecitabine, oxaliplatin and bevacizumab followed by an expanded cohort in previously untreated metastatic colorectal cancer. Invest New Drugs 32: 330-339.

Summy JM, Gallick GE (2003) Src family kinases in tumor progression and metastasis. Cancer Metastasis Rev 22: 337-358.

Talamonti MS, Roh MS, Curley SA, Gallick GE (1993) Increase in activity and level of pp60c-src in progressive stages of human colorectal cancer. J Clin Invest 91: 53-60.

Therasse P, Arbuck SG, Eisenhauer EA, Wanders J, Kaplan RS, Rubinstein L, Verweij J, Van Glabbeke M, van Oosterom AT, Christian MC, Gwyther SG (2000) New guidelines to evaluate the response to treatment in solid tumors. European Organization for Research and Treatment of Cancer, National Cancer Institute of the United States, National Cancer Institute of Canada. J Natl Cancer Inst 92: 205-216.

Trevino JG, Summy JM, Lesslie DP, Parikh NU, Hong DS, Lee FY, Donato NJ, Abbruzzese JL, Baker CH, Gallick GE (2006) Inhibition of SRC expression and activity inhibits tumor progression and metastasis of human pancreatic adenocarcinoma cells in an orthotopic nude mouse model. Am J Pathol 168: 962-972.

Van Cutsem E, Twelves C, Cassidy J, Allman D, Bajetta E, Boyer M, Bugat R, Findlay M, Frings S, Jahn M, McKendrick J, Osterwalder B, Perez-Manga G, Rosso R, Rougier P, Schmiegel WH, Seitz JF, Thompson P, Vieitez JM, Weitzel C, Harper P. Xeloda Colorectal Cancer Study Group (2001) 
Oral capecitabine compared with intravenous fluorouracil plus leucovorin in patients with metastatic colorectal cancer: results of a large phase III study. J Clin Oncol 19: 4097-4106.

Verbeek BS, Vroom TM, Adriaansen-Slot SS, Ottenhoff-Kalff AE, Geertzema JG, Hennipman A, Rijksen G (1996) c-Src protein expression is increased in human breast cancer. An immunohistochemical and biochemical analysis. J Pathol 180: 383-388.

Vultur A, Buettner R, Kowolik C, Liang W, Smith D, Boschelli F, Jove R (2008) SKI-606 (bosutinib), a novel Src kinase inhibitor, suppresses migration and invasion of human breast cancer cells. Mol Cancer Ther 7: 1185-1194.

XELODA Full Prescribing Information (2013) Genentech, San Francisco, CA.

(c) (1) (2) (2) This work is licensed under the Creative Commons (c) ${ }_{\mathrm{BY}} \mathrm{NC}$ SA Attribution-NonCommercial-Share Alike 3.0 Unported License. To view a copy of this license, visit http://creativecommons. org/licenses/by-nc-sa/3.0/

Supplementary Information accompanies this paper on British Journal of Cancer website (http://www.nature.com/bjc) 